\title{
Contrasting feeding patterns among species of fish larvae from the tropical Andaman Sea
}

Pia Østergaard ${ }^{1}$, Peter Munk ${ }^{2}$ and Vudhichai Janekarn ${ }^{3}$

${ }^{1}$ Department of Zoology, The Natural History Museum, London SW7 5BD, England.

${ }^{2}$ Danish Institute for Fisheries Research, Charlottenlund Castle, DK-2920 Charlottenlund, Denmark.

${ }^{3}$ Phuket Marine Biological Center, P.O. Box 60, Phuket Province 83000, Thailand.

\section{CORRESPONDING AUTHOR}

Peter Munk,

Danish Institute for Fisheries Research, Charlottenlund Castle, DK-2900 Charlottenlund, Denmark.

Email:pm@dfu.min.dk

Fax: +453396 3434

Telephone: +45 33963409 
Abstract. Feeding habits of tropical fish larvae were analysed in a comparative study on four species of larvae (Scorpaenodes sp., Carangoides sp., Acanthocepola sp. and Cynoglossus sp.) from the Andaman Sea. We investigated the influence of morphological characteristics, and looked for common patterns in larval prey preference. Gut contents of a total of 300 larvae were examined and compared to environmental zooplankton composition. During ontogeny all four species increased their preferred prey size and their stomach fullness. Another common characteristic of the larval feeding was a uniform width of the relative prey size spectrum across all larval size classes, and the width of the spectrum was of approximately same magnitude in all species. However, when including taxonomic composition of prey, our findings also showed prominent differences among the four species. Scorpaenodes sp. preferred abundant and large prey taxa, Acanthocepola sp. and Carangoides sp. preferred large but less common prey taxa, when Cynoglossus sp., which had the relatively smallest mouth size, preferred groups of smaller sized prey. Differences in morphology, and the rate with which morphological changes takes place apparently have great influence on diet composition and prey preference in the four species studied.

\section{Introduction}

Prey availability and feeding success are of prime importance in the early life of fish. In order to keep a high growth rate and survive to recruitment, the larvae have to maximize their food intake, finding the appropriate prey items and being efficient feeders. Hence, defining dietary preferences for the early stages is important elements in the assessment of feeding conditions and larval chances of meeting food requirements (Robichaud-LeBlanc et al. 1997). Observations on larval prey preference are mainly based on analyses of gut contents. Some larval fish may be opportunistic feeders, ingesting prey in direct proportion to their abundance in the environment when other larval fish show preference for prey of a certain size (Scharf et 
al. 2000). Fish larvae are flexible and adaptive in their foraging behaviour (Munk 1992, 1995), and the actual prey intake is to be seen as the outcome of a process influenced by interacting morphological, behavioural, physiological, as well as environmental factors.

A factor of prime importance in the process of prey search and capture is the morphology of the larva. Larval structure and developmental stage determines its ability to detect, approach and attack prey, while constraints such as the size of the mouth set the maximum size of prey that they can possibly ingest (e.g. Govoni et al. 1983; Munk 1992; Sabatés and Saiz 2000; Scharf et al. 2000; Young and Davis 1992). Hence, feeding behaviour will change during larval ontogeny depending on the morphological changes taking place (Sabatés and Saiz 2000). For example, during growth the mouth size will increase and the larval swimming and manoeuvring abilities will be improved, this increasing the efficiency of foraging. Additionally, feeding is dependent on the morphology of prey. At increasing size the prey might improve their defence mechanisms (e.g. spines) and mobility (Scharf et al. 2000), and even though larval fish become better hunters during ontogeny, their potential prey also becomes better at avoiding an attack.

Diet breadth of a fish species has often been described by the range of prey sizes found in the gut. However, range is a poor measure, among other things because of its dependence on sample size. It is more relevant to describe the diet breadth on a ratio scale, relating prey size to predator size. Pearre (1986) suggested the use of standard deviation because it is independent of sample size and he defined an index (SLH) as the standard deviation of logarithmically transformed prey size data. Based on an investigation of 43 predator/prey relationships, Pearre (1986) proposed that the ratio-based spectrum remains constant during growth of the fish and the size spectrum of the ingested food resource cannot be increasing as larval fish grows. Likewise, studies by e.g. Munk $(1992,1997)$ and Sabatés and Saiz (2000) indicate constancy in the relative prey size preference spectrum. However, 
the hypothesis has been much debated, and several authors question its general applicability (e.g. Gonzáles-Quirós and Anadón 2001; Houde, 1997; Pepin and Penney 1997).

As part of a larger study of the pelagic community in the Andaman Sea (Munk et al. in press; Nielsen et al. in press) fish larvae were sampled along a series of cross-shelf transects. The fish larvae and zooplankton sampled at a specific station was used in a study of feeding habits of four different larval species, Scorpaenodes sp., Carangoides sp., Acanthocepola sp. and Cynoglossus sp. The specific goals of the study were to describe common patterns and variability in the larval feeding and prey preference, focusing on the relative influence of 1) prey type and size, 2) species characteristics and 3) ontogenetic changes. Further emphasis was given the evaluation of whether prey size of maximal preference of these larvae is a constant ratio of predator mouth size, and whether the width of the ratio-based preference spectra is constant.

\section{Materials and methods}

Fish larvae and their potential zooplankton prey were collected at the position $8^{\circ} 24^{\prime} \mathrm{N}$ $97^{\circ} 53^{\prime} \mathrm{E}$ during January 16, 1999. The station was positioned in a cross-shelf transect of sampling stations used during previous surveys, and was chosen while earlier surveys have shown this position of high productivity and plankton abundances (Station 18 in Munk et al. in press). Bottom depth at station was $69 \mathrm{~m}$. Fish larvae were sampled using a ring-net of $2 \mathrm{~m}$ diameter, equipped with a black, $14 \mathrm{~m}$ long net of $1 \mathrm{~mm}$ mesh size. The net was hauled in oblique tows from surface to $60 \mathrm{~m}$ depth, at ships speed of 3 knots and paying and retrieving

the wire at speeds of 25 and $15 \mathrm{~m} \mathrm{~min}^{-1}$, respectively. A flow meter in the centre of the ring measured the volume of water entering the net. The tows were carried out every 3 hours between 05:00 and 23:00h (local time). Each tow lasted around 20-30 min. All fish larvae sampled were sorted on deck and stored in $96 \%$ ethanol. Following each of the ring net hauls, 
the meso-zooplankton was collected using a submersible pump (Grundfos SP 16) equipped with a $250 \mu \mathrm{m}$ meshed conical net. The pump was lowered from the surface to $60 \mathrm{~m}$ and subsequently retrieved. Samples from this net were preserved in $4 \%$ formaldehyde, and sorting of the samples took place after the cruise.

In the laboratory, the fish larvae from the samples were identified to family level. Some taxa dominated by number, and among these we chose four species of conspicuous differences in morphology for detailed studies of feeding patterns. These fish larvae were further identified to genus as the following: Scorpaenodes sp. (family: Scorpaenidae), Carangoides sp. (family: Carangidae), Acanthocepola sp. (family: Cepolidae) and Cynoglossus sp. (family: Cynoglossidae) (Fig. 1). We measured larval standard length (SL), body depth (BD, maximal distance from ventral to dorsal side) and mouth size (ML, length of the lower jaw/maxilla from the tip to the angle of the maxilla bone viewed from the side). Standard measurements are illustrated in Janekarn et al. (2002). Standard length (SL) was measured to nearest $0.05 \mathrm{~mm}$, when $\mathrm{BD}$ and $\mathrm{ML}$ were measured to nearest $0.02 \mathrm{~mm}$. After measuring the larva, the stomach was opened with fine needles and stomach contents were analysed. Predominant food items were copepods (>98\% by number) and only these were considered in the further analysis. The condition of many of the copepods made taxonomic identification difficult and identification was either non-specific (to nauplius or copepod stage) or to the following order/family groups: Calanoida/spp., Cyclopoida/Oithonidae, Poecilostomatoida/Corycaeidae, Poecilostomatoida/Oncaeidae and Harpacticoida/spp. The copepods were counted and their maximal width and cephalothoraxlength were measured (to nearest $0.02 \mathrm{~mm}$ ). In addition, aliquots of copepods from the related net-sampled zooplankton were identified and measured following the same procedures. Only taxa observed in the gut contents analysis were considered. 
In the analysis we compared abundance of copepods within size intervals. However, the abundance of copepods declines markedly with size, and to ensure reasonable abundances also in the intervals of larger sized specimen, we used logarithmically increasing intervals. The interval of smallest copepods was set to a midpoint of $0.050 \mathrm{~mm}$, and subsequent interval midpoints were spaced $\log 10$ distances of 0.1003 . Hence, midpoints were $0.050,0.063,0.079,0.100,0.126,0.159,0.200,0.252,0.317,0.400,0,504,0.635,0.800$, $1.008,1.270,1.600,2.016$ and $2.540 \mathrm{~mm}$. Prey preference by larvae was quantified with Chesson (1978) preference index $\alpha$. The index, ranging from 0 to 1 , is calculated as: $\alpha=$ $\left(r_{i} / p_{i}\right)\left(\Sigma r_{i} / p_{i}\right)^{-1},(i=1, \ldots, m)$ where $r_{i}=$ the proportion of prey item $i$ in the larval diet, $p_{i}=$ the proportion of prey item $i$ in the environment, and $m=$ the total number of prey types (size and/or taxonomic group). Prey items were pooled for larval size groups of $1 \mathrm{~mm}$ intervals before calculating the indices. The distribution of indices along the prey size scale is the dietary prey size spectrum, and the mean prey size of this spectrum (= prey of maximum preference), as well as the standard deviation (the SLH-index; Pearre 1986), were calculated assuming normal distribution of the log scale data (log normality). All statistical analyses were carried using the procedure GLM in Statistical Analysis System®.

\section{Results}

The abundance of fish larvae at the sampled station reached densities up to $6.7 \mathrm{~m}^{-2}$. Of the four species 89 Scorpaenodes sp., 80 Carangoides sp., 99 Acanthocepola sp. and 32 Cynoglossus sp. larvae were examined. The larvae ranged in size from 3.6 to $12.5 \mathrm{~mm}$ SL for Scorpaenodes sp. (mean: $5.8 \mathrm{~mm}$ ), from 1.7 to $10.4 \mathrm{~mm}$ SL for Carangoides sp. (mean: 5.9 $\mathrm{mm}$ ), from 4.0 to $23.4 \mathrm{~mm}$ SL for Acanthocepola sp. (mean: $7.9 \mathrm{~mm}$ ) and from 4.0 to 15.0 mm SL for Cynoglossus sp. (mean: $6.8 \mathrm{~mm}$ ) (Fig. 2). The four species of fish larvae studied displayed conspicuous morphological differences in body shape and pigmentation pattern 
(Figs. $1 \& 3$ ). The relative body depth (BD in proportion to SL) of the larvae was generally higher for the Scorpaenodes sp. and Carangoides sp than for the Acanthocepola $\mathrm{sp}$ and Cynoglossus sp. (Fig. 3a). Differences were significant between species (ANCOVA, all pairwise comparisons: $\mathrm{p}<0.0001$ ), except between Scorpaenodes sp. and Carangoides sp. $(\mathrm{p}=0.9)$. Decline in relative body depth during ontogeny was insignificant for Scorpaenodes sp. (ANOVA, $\mathrm{p}=0.27$ ), but significant for the other species (ANOVA, for all: $\mathrm{p}<0.001$ ). Furthermore, the mouth morphology differed among species, expressed by the relative gape size (ML in proportion to SL) of the individual species (Fig. 3b). Scorpaenodes sp. had the largest relative gape size $(\sim 25 \%)$ when Cynoglossus sp. had the smallest $(\sim 10 \%)$. Differences between species were significant in all pairwise comparisons (ANCOVA, for all: $\mathrm{p}<0.0001)$. Decline in relative gape size during ontogeny was insignificant for Acanthocepola sp. (ANOVA, $\mathrm{p}=0.06$ ), but significant for the other species (ANOVA, for all: $\mathrm{p}<0.0001$ ). Copepods dominated the zooplankton community ( $>98.5 \%$ by number). Their estimated densities varied from 1800 to 9300 individuals $\mathrm{m}^{-3}$, depending on sampling time. The distinguished groups of copepods differed in size composition and relative abundance (Fig. 4a), as well as in morphology expressed by the relationship between their length and width (Fig. 4b).

For the four species of fish larvae we found high feeding incidences (88-100\%) during all daytime sampling sequences (Fig. 5a). All larvae had empty guts at the early morning sampling (05:00 local time) and maximal incidence was reached at the subsequent sampling 1/1/2 hour after sunrise, which took place around 6:30. Feeding incidence declined after sunset at 18:30, some larvae still had gut contents during the subsequent sampling (especially Acanthocepola sp), which was probably due to remains of food from the daytime feeding. Gut fullness measured by the mean number of prey in larval guts, followed the increase and decline described for feeding incidence. Most of the larvae had a peak in gut 
fullness in the morning and again in the afternoon (Fig. 5b). This pattern was most obvious for Carangoides sp. and Acanthocepola sp., whereas Cynoglossus sp. only showed a morning peak and Scorpaenodes sp. an afternoon peak.

Carangoides sp. larvae generally had the largest amount of prey in their guts (on average 15 prey per larva). Acanthocepola sp. had on average ca. 12 prey per larvae, Cynoglossus sp. on average 9 prey per larva and Scorpaenodes sp. 8 prey per larva. Gut fullness increased during ontogeny for Carangoides sp., Scorpaenodes sp. and Acanthocepola sp., whereas no increase in gut fullness during ontogeny was observed for Cynoglossus sp. (Fig. 6). Composition of gut contents differed among species and size groups of larvae. Scorpaenodes sp. larvae less than $7.0 \mathrm{~mm}$ SL had a mix of Calanoida, Oncaeidae and Corycaeidae in their gut (Fig. 7a). In the larger larvae (larger than $7.0 \mathrm{~mm} \mathrm{SL}$ ) calanoids dominated in the gut contents (> 85\%). The main prey of Carangoides sp. were Oncaeidae and Corycaeidae (between 47 - $61 \%$ ) (Fig. 7b). Small Carangoides sp. larvae ate a mix of Calanoida, Oncaeidae, Corycaeidae and Harpacticoida. In the larger Carangoides sp. larvae (greater than $9.0 \mathrm{~mm} \mathrm{SL}$ ) the harpacticoids were of little importance. In the guts of Acanthocepola sp., the main items were Oncaeidae and Corycaeidae (between 42 - $71 \%$ ) (Fig. 7c). The diet composition for Acanthocepola sp. was very similar to that of Carangoides sp. and during ontogeny the relative importance of harpacticoids eaten by smaller larvae declined gradually. Finally, the guts of especially smaller larval Cynoglossus sp. had a remarkably high prevalence of harpacticoids (between 36 - 67\%), while during ontogeny of this species the relative importance of Oncaeidae increased (from 7\% to 36\%) (Fig. 7d).

In accordance with the observed variation in prey composition, mean prey size also differed among species and varied during ontogeny (Fig. 8, black circles). The rate of change in mean prey size (width of prey), i.e. the slopes of the regressions in figure 8 , differed significantly among most species. In pairwise comparisons of slopes only Carangoides sp. 
and Acanthocepola sp. were insignificantly different (ANCOVA, $\mathrm{p}=0.22$ ), all other combinations were significant (ANCOVA, for all: $\mathrm{p}<0.05$ ). The calculated preferences followed the same pattern (i.e. difference among species and change during ontogeny) as for gut contents (Fig. 8, open squares). Comparison between width in guts and preferred width showed that larval preference was skewed towards the larger sizes in the environment. The width of the prey preference spectrum (SLH-index) was calculated for a range of larval size groups, and the change during ontogeny was investigated by linear regressions (Fig. 9). The width of the prey size spectra was on average 0.14 , and did not show any significant relationship to larval size, i.e. the slopes of the regressions were insignificantly different from zero (ANOVA, for all: $\mathrm{p}>0.19$ ).

Larvae not only selected for size, but also showed different preference for different taxa of equally sized prey. This was apparent when comparing size-preference curves for each taxonomic prey group by larvae within the 5-10 mm size interval (Fig. 10). Scorpaenodes sp. which showed increasing preference for calanoids during ontogeny (Fig. 7a), preferred specimens larger than $250 \mu \mathrm{m}$ (Fig. 10a) when the average size of calanoids in the zooplankton was only $140 \mu \mathrm{m}$. Further, the Scorpaenodes sp. supplemented the diet with Oncaeidae and Corycaeidae, of which they also preferred specimens larger than average. Acanthocepola sp. and Carangoides sp. showed similarities in their prey preferences. Their diet included many Corycaeidae, Oncaeidae and in smaller larvae also Harpacticoida (Fig. 7b \& c), which all were the least abundant in the zooplankton. Besides their taxonomic preference, they also showed a clear selection for larger-sized specimens of those taxa. However, Carangoides sp. preferred Oncaeidae of about 250-400 $\mu \mathrm{m}$, Corycaeidae of about 200-400 $\mu \mathrm{m}$ and Harpacticoida of about $140 \mu \mathrm{m}$ (Fig. 10b), which were all larger than the average size of these groups in the environment, whereas Acanthocepola sp. preferred Oncaeidae of about $250 \mu \mathrm{m}$, Corycaeidae of about 200-250 $\mu \mathrm{m}$ and Harpacticoidae of about 
$140 \mu \mathrm{m}$ (Fig. 10c). During ontogeny the diet of Cynoglossus sp. shifted from dominance of small sized nauplii to the larger sized Oncaeidae (Fig. 7d). It is clear from this study, that Cynoglossus sp. of all four larvae prefers the smallest prey (Fig. 10). In summary, for all larval species the Corycaeidae and Harpacticoida were highly preferred groups in their respective size ranges, while the relative preference of the groups Oncaeidae and Calanoida differed among larval species. Nauplii were generally of very low preference.

During ontogeny the relative size of maximally preferred prey declined, both when expressed by prey width against larval mouth size, and as prey length against larval length (Fig. 11a, b). The decline is significant for all illustrated comparisons (ANOVA, for all: $\mathrm{p}<0.05)$, except the prey width/mouth size for Scorpaenodes $\mathrm{sp} .(\mathrm{p}=0.78)$. The relative size of preferred prey differed among species, however, the characteristics differed dependent on the type of comparison. For example, Cynoglossus sp. preferred wider prey relative to its mouth size than the other species of larvae (Fig. 11a), when it preferred smaller prey than the other in the case where relative prey size is expressed by prey length against larval length (Fig. 11b).

\section{Discussion}

Our study showed a series of characteristic feeding patterns and differences among the four larvae. Common to Scorpaenodes sp., Carangoides sp., Acanthocepola sp. and Cynoglossus sp. was an increase in preferred prey size and stomach fullness during ontogeny. Another characteristic of larval feeding was the uniform width of the relative prey size spectrum. Our measure of the relative width (SLH-index) was not only constant across the larval sizes of our investigation, but was also approximately of the same magnitude (0.14) in all species. Likewise, constancy in the SLH-index during ontogeny has been observed for six different species of myctophiform larval fish (ca. 5 - $17 \mathrm{~mm}$ ) from the Mediterranean (Sabatés and Saiz 2000). Scharf et al. (2000) found a constant relative width of size preference spectrum for 18 
species of juvenile and adult fish caught off the northeast coast of the US. These fishes were mainly 60 - $200 \mathrm{~mm}$, hence of a larger size range than in the present study. For even larger fish (> $500 \mathrm{~mm}$ ), these authors observed a negative relationship in the SLH-index with fish size. A negative relationship in SLH was also observed in the largest larvae (7 - $15 \mathrm{~mm})$ of blue whiting, Micromesistius pautassou from the North Spanish Coast (Gonzáles-Quirós and Anadón 2001). Gonzáles-Quirós and Anadón (2001) suggested that the decrease in SLHindex in large larvae was due to a low abundance of large prey, hence the large larvae have difficulties encountering large prey, although they were capable of ingesting them. However, in the cited studies the SLH calculations were based on gut content only, and not "calibrated" by calculating preferences. For comparative purposes the calculated widths of prey size spectra should preferably be independent of prey composition in the environment. In the cited cases (Gonzáles-Quirós and Anadón 2001; Sabatés and Saiz 2000; Scharf et al. 2000) interpretations of changes are obviously influenced by the explicit prey availability.

A positive relationship between average prey size and size of larvae has been reported for several species of fish larvae (e.g. DeVries et al. 1998; Govoni et al. 1983; Kellermann 1990; Pepin and Penney 1997; Sabatés and Saiz 2000; Young and Davis 1990), but the proportionality differs among species, as observed in the present study. Pepin and Penney (1997) and Sabatés and Saiz (2000) also found that even closely related species differed in the rate with which average size of ingested prey increased during their ontogeny. Sabatés and Saiz (2000) also found that observed difference in prey preference between species to a great extent was related to morphological differences between larval species. Obviously, the larvae of the present study differed markedly in morphology, and our analysis indicates that different feeding strategies of larvae to some extent are related to differences in larval morphology. Dependent on relative height of the body we will expect differences in swimming and manoeuvring abilities, which will influence feeding behaviour and preference 
aspects. For example, the two species of largest relative body depth, Scorpaenodes sp. and Carangoides sp., were the species that relative to their length preferred the largest prey organisms. Hence, when we for Scorpaenodes sp. registered less stomach contents by number (about 8 prey per stomach) than for e.g. Carangoides sp. this was counterbalanced by the larger size, and biomass, of the prey items. Also the differences between Acanthocepola sp. and Carangoides sp. might be related to their differences in morphology. The mouth size and body depth differed between these species, and when the species showed similarities in their taxonomic preferences their prey size preference of the same prey taxa was different. Further, Cynoglossus sp. with a relatively small mouth and body depth, was the species of all four that preferred the smallest prey relative to its length. In summary, these findings suggest distinct feeding patterns used by the four species of fish larvae: 1) Scorpaenodes sp. Feeding on abundant and large prey. A common prey type (calanoids) was preferred, but larger than average prey of that type was eaten. 2) Acanthocepola sp. and Carangoides sp. Feeding on less abundant and large prey. A less common prey type was preferred (e.g. Oncaeidae and Corycaeidae), and larger than average prey of that type was eaten. 3) Cynoglossus sp. Feeding on smaller sized prey. Both common (e.g. nauplii) and less abundant (e.g. harpacticoids) prey were important in the diet when larger prey was less available due to restrictions by gape size and body depth.

Differences in prey selection between species, and size groups of the same species, might reduce inter- and intra-specific competition for the food resource. Our findings of constancy in the relative niche breadth imply that during growth the larvae invades new niches of prey sizes, hence they do not compete with smaller sized larvae for the smaller sized prey. As pointed out by Krebs and Turingan (2003) the foraging of larvae is not only dependent on what the larvae are capable of ingesting, but also on the actual environmental plankton composition. Govoni et al. (1983) found that when food is abundant, diet overlap is 
very common. Pepin and Penney (2000) observed in their study that larval predation pressure on the zooplankton community was very low, but found that larval fish gradually shifted their diet to larger prey items, this limiting competition. However, they also found a substantial overlap in the types and sizes of prey eaten by different species that co-occurred, and concluded that since the predation pressure on the zooplankton community was generally low there was less reason to partition resources. Accordingly, the observed overlap in prey eaten by the fish larvae Carangoides sp. and Acanthocepola sp. does not necessarily imply they compete strongly for food, when the food might be of sufficient abundance to lessen the competition.

Differences in peak abundance of larval species, as seen in the concurrent study described in Munk et al. (in press), as well as differences in morphology and the rate with which morphological changes take place, would be major determinants of larval feeding habits. In this study we observed a series of characteristic patterns of larval feeding, but also found considerable ontogenetic and interspecific variabilities. The strategy of each species differs, depending on capabilities and possibilities, and we see the comparative approach as a useful method for evaluating factors which determine prey preference and larval food intake. Because of the high species diversity in tropical waters such comparative information is required for improved understanding of the early life of fish in these waters.

Acknowledgements. We are grateful to the staff of the Marine Biological Productivity Unit (PMBC) and to the crew of R/V Chrakratong Tongyai for their efficient assistance during laboratory and field work. Special thanks to Jaratsri Engchuan for her thorough work on the fish larvae. This work is supported by Department of Fisheries (Thailand), the Danish Institute for Fisheries Research, and by a DANIDA grant (\#104.P.3). 


\section{References}

Chesson J (1978) Measuring preference in selective predation. Ecology 59: 211-215.

DeVries DR, Bremigan MT, Stein RA (1998) Prey selection by larval fishes as influenced by available zooplankton and gape limitation. Trans Am Fish Soc 127: 1040-1050.

González-Quirós R, Anadón R (2001) Diet breadth variability in larval blue whiting as a response to plankton size structure. J Fish Biol 59: 1111-1125.

Govoni JJ, Hoss DE, Chester AJ (1983) Comparative feeding of three species of larval fishes in the Northern Gulf of Mexico: Brevoortia patronus, Leiostomus xanthurus, and Micropogonias undulatus. Mar Ecol Prog Ser 12: 189-199.

Janekarn V, Munk P, Sawangarreruks S (2002) Proceedings of the regional workshop on ecology of tropical mesoplankton and fish larvae. Spec Publ Phuket mar Biol Cent 27: 39-41.

Kellermann A (1990) Food and feeding dynamics of the larval Antarctic fish Nototheniops larseni. Mar Biol 106: 159-167.

Krebs JM, Turingan RG (2003) Intraspecific variation in gape-prey size relationships and feeding during early ontogeny in red drum, Sciaenops ocellatus. Env Biol Fish 66: 75-84.

Munk P (1992) Foraging behaviour and prey size spectra of larval herring Clupea harengus. Mar Ecol Prog Ser 80: 149-158. 
Munk P (1995) Foraging behaviour of larval cod (Gadus morhua) influenced by prey density and hunger. Mar Biol 122: 205-212.

Munk P (1997) Prey size spectra and prey availability of larval and small juvenile cod. J Fish Biol 51 (Suppl A): 340-351.

Munk P, Bjørnsen PK, Boonruang P, Fryd M, Hansen PJ, Janekarn V, Limtrakulvong V, Nielsen TG, Schou O, Satapoomin S, Sawangarreruks S, Thomsen HA, Østergaard JB (2004) Variation in hydrography and plankton dynamics across the shelf and shelf slope of the tropical Andaman Sea, I: Assemblages of meso-zooplankton and fish larvae. Mar Ecol Prog Ser 00: 000-000

Nielsen TG, Bjørnsen PK, Boonruang P, Fryd M, Hansen PJ, Janekarn V, Limtrakulvong V, Munk P, Schou O, Satapoomin S, Sawangarreruks S, Thomsen HA, Østergaard JB (2004) Variation in hydrography and plankton dynamics across the shelf and shelf slope of the tropical Andaman Sea, I: Variability in hydrography, bacteria and protistplankton. Mar Ecol Prog Ser 00: 000-000

Pearre S (1986) Ratio-based trophic niche breadths of fish, the Sheldon spectrum, and the size-efficiency hypothesis. Mar Ecol Prog Ser 27: 299-314.

Pepin P, Penney RW (1997) Patterns of prey size and taxonomic composition in larval fish: are there general size-dependent models? J Fish Biol 51 (Suppl A): 84-100. 
Pepin P, Penney R (2000) Feeding by a larval fish community: impact on zooplankton. Mar Ecol Prog Ser 204: 199-212.

Robichaud-LeBlanc KA, Courtenay SC, Hanson JM (1997) Ontogenetic diet shifts in age-0 striped bass, Morone saxatilis, from the Miramichi River estuary, Gulf of St. Lawrence. Can J Zool 75: 1300-1309.

Sabatés A, Saiz E (2000) Intra- and interspecific variability in prey size and niche breadth of myctophiform fish larvae. Mar Ecol Prog Ser 201:261-271.

Scharf FS, Juanes F, Rountree RA (2000) Predator size- prey size relationships of marine fish predators: interspecific variation and effects of ontogeny and body size on trophic-niche breadth. Mar Ecol Prog Ser 208: 229-248.

Young JW, Davis TLO (1990) Feeding ecology of larvae of southern bluefin, albacore and skipjack tunas (Pisces: Scombridae) in the eastern Indian Ocean. Mar Ecol Prog Ser 61: 1729.

Young JW, Davis TLO (1992) Feeding ecology and interannual variations in diet of larval jack mackerel, Trachurus declivis (Pisces: Carangoides sp.), from coastal waters of eastern Tasmania. Mar Biol 113: 11-20. 


\section{Figure legends}

Fig. 1. Larvae collected from Andaman Sea during Cruise 1/99. a) Scorpaenodes sp., b) Carangoides sp., c) Acanthocepola sp. and d) Cynoglossus sp.

Fig. 2. Scorpaenodes sp., Carangoides sp., Acanthocepola sp. and Cynoglossus sp. Lengthfrequency distributions of larvae examined for stomach contents.

Fig. 3. Scorpaenodes sp., Carangoides sp., Acanthocepola sp. and Cynoglossus sp. Body depth (BD) and lower jaw length (ML) in proportion to standard length (SL) as a function of standard length (SL).

Fig. 4. a) Abundance of the dominant copepod groups of zooplankton available to fish larvae. Data from all the related zooplankton net-samples are pooled together. b) Copepod length width relation for the dominant copepod groups in the zooplankton.

Fig. 5. Scorpaenodes sp., Carangoides sp., Acanthocepola sp. and Cynoglossus sp. a) Feeding incidence, showing relationship between time of day and proportion of larvae feeding and b) mean number of prey per larva in relation to time of day. Approximate times of sunrise: 6:00h and sunset: $18.00 \mathrm{~h}$.

Fig. 6. Scorpaenodes sp., Carangoides sp., Acanthocepola sp. and Cynoglossus sp. Relationship between number of prey in stomach and size of larvae. Linear regressions are indicated.

Fig. 7. Scorpaenodes sp., Carangoides sp., Acanthocepola sp. and Cynoglossus sp.

Cumulative diet composition in relation to larval size class. 
Fig. 8. Scorpaenodes sp., Carangoides sp., Acanthocepola sp. and Cynoglossus sp. Mean and standard deviation of log transformed prey widths in relation to mean standard length (SL) of larvae in groups (closed circles). The value for each mean prey width is based on values for at least three prey entries, which may reflect data from several fish larvae. Prey width of maximal preference in relation to mean standard length (SL) of larvae in groups is also included (open squares). Linear regressions are indicated.

Fig. 9. Scorpaenodes sp., Carangoides sp., Acanthocepola sp. and Cynoglossus sp. The width of prey size spectra, expressed by the standard deviation of log transformed prey width data (SLH-index) as a function of larval size.

Fig. 10. Scorpaenodes sp., Carangoides sp., Acanthocepola sp. and Cynoglossus sp. Chesson index of preference along an axis of $\log _{10}$ size intervals of prey width for fish larvae of size interval: $5-10 \mathrm{~mm}$. Preference of each copepod group is illustrated by separate curves. Preferences equal one in each fish species.

Fig. 11. Scorpaenodes sp., Carangoides sp., Acanthocepola sp. and Cynoglossus sp. a) Prey width of maximum preference in proportion to larval mouth size as a function of larval standard length. b) Prey length of maximum preference in proportion to larval length as a function of larval standard length. 


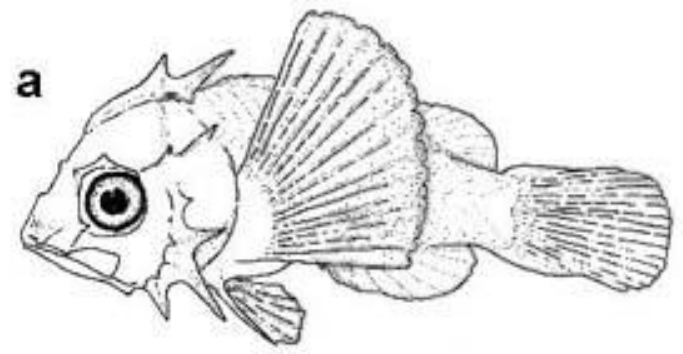

b

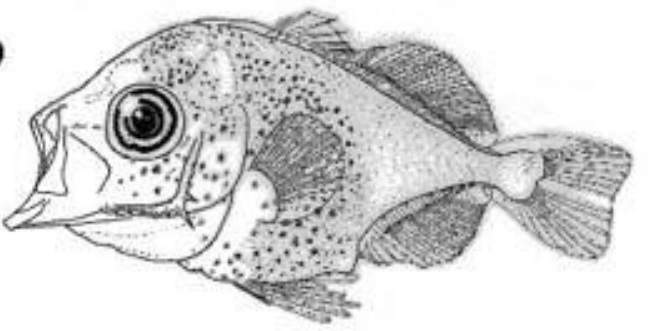

c
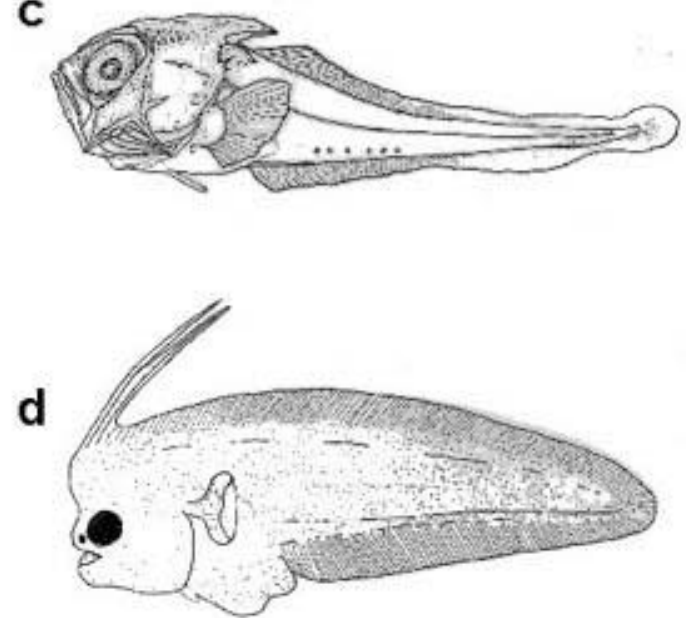

Figure 1 

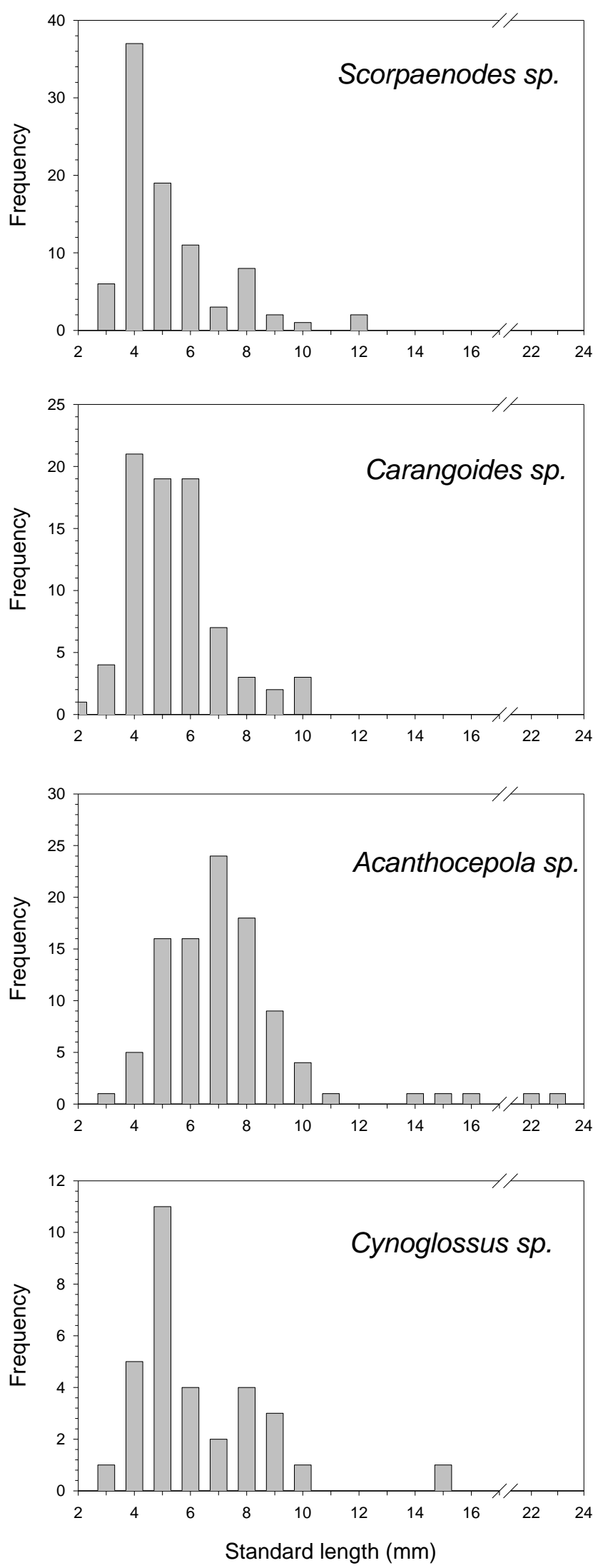

Figure 2 

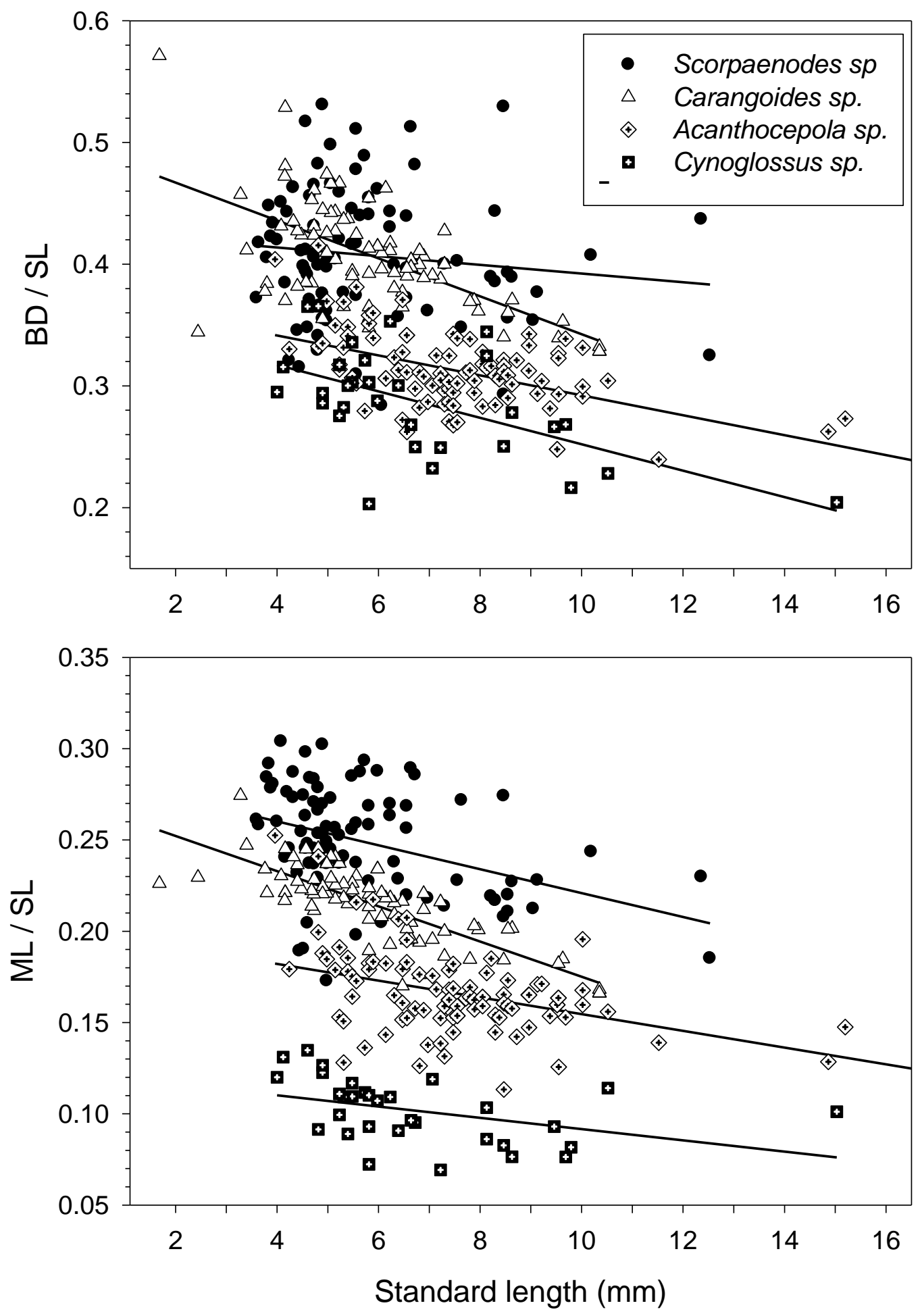

Figure 3 
a)

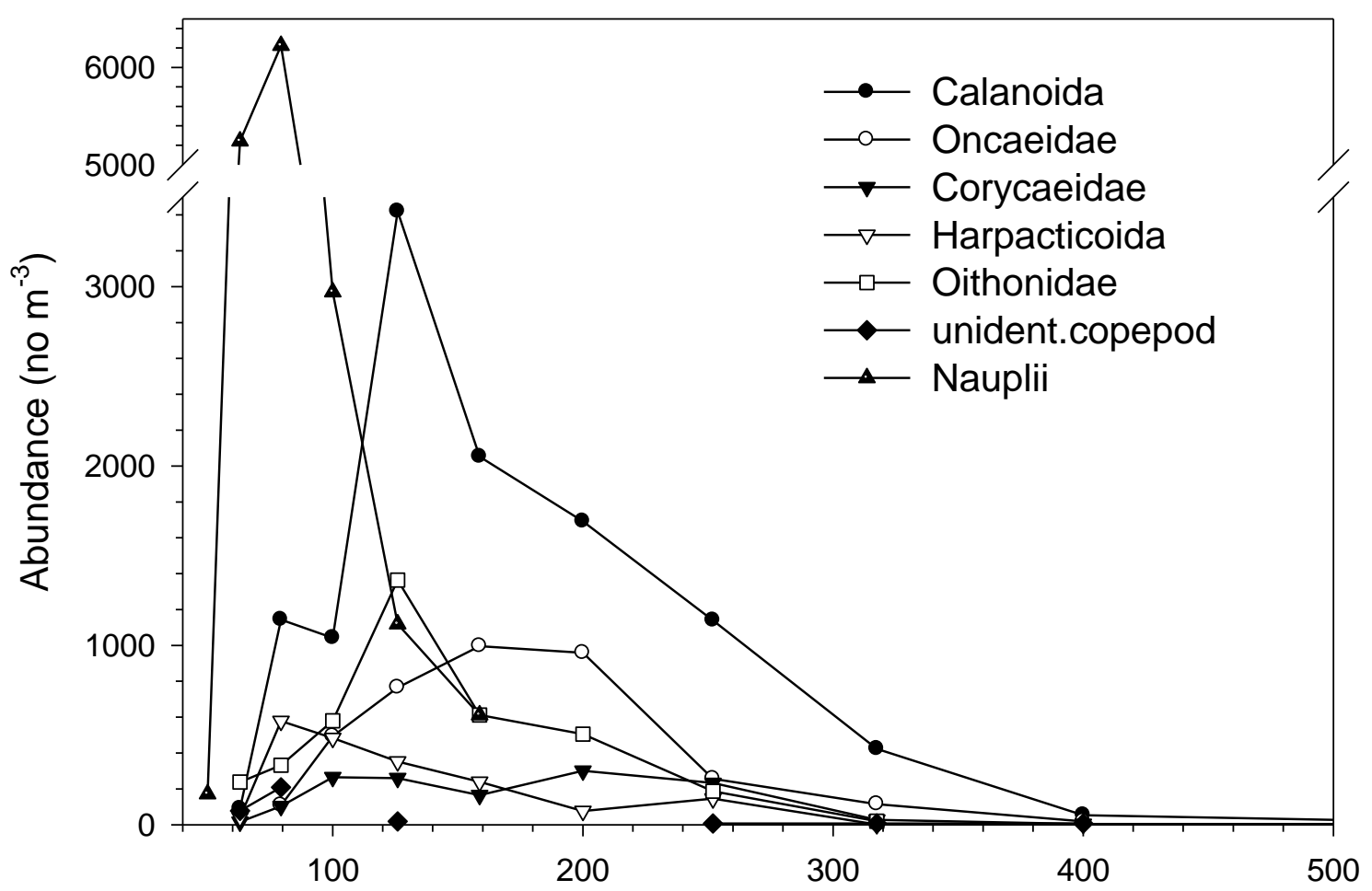

b) Copepod width interval $(\mu \mathrm{m})$

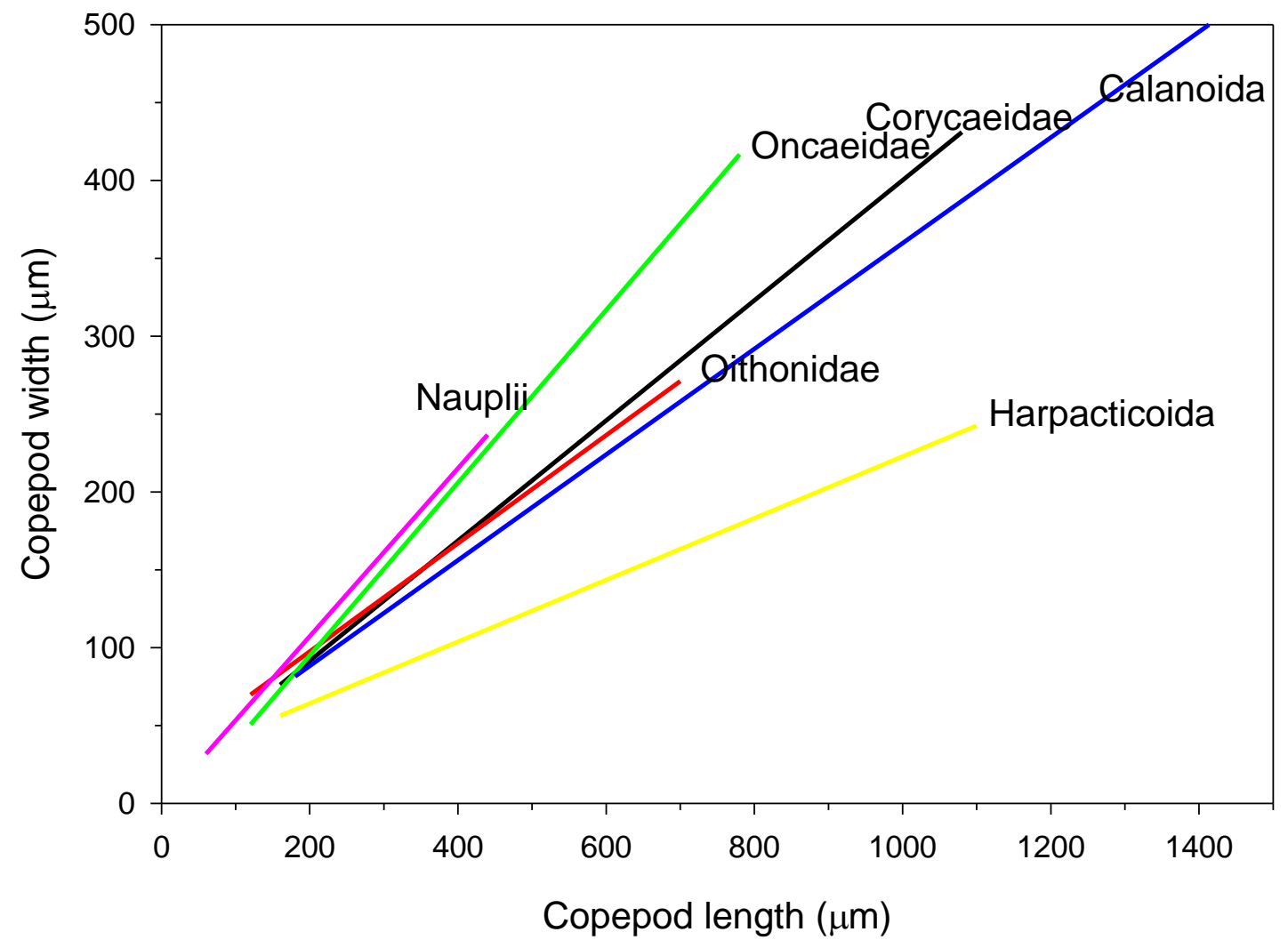

Figure 4 
a)
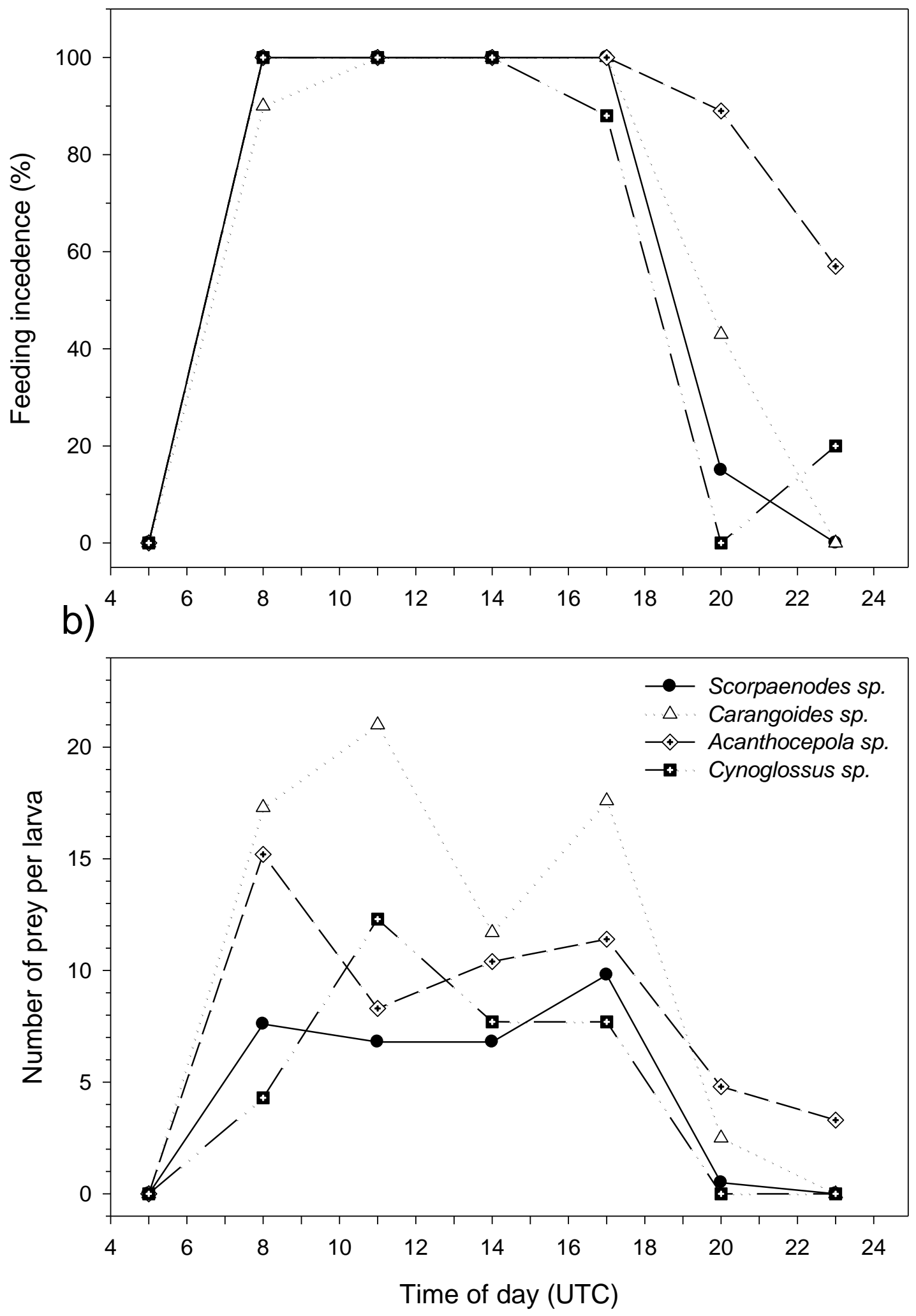

Figure 5 
Figure 6

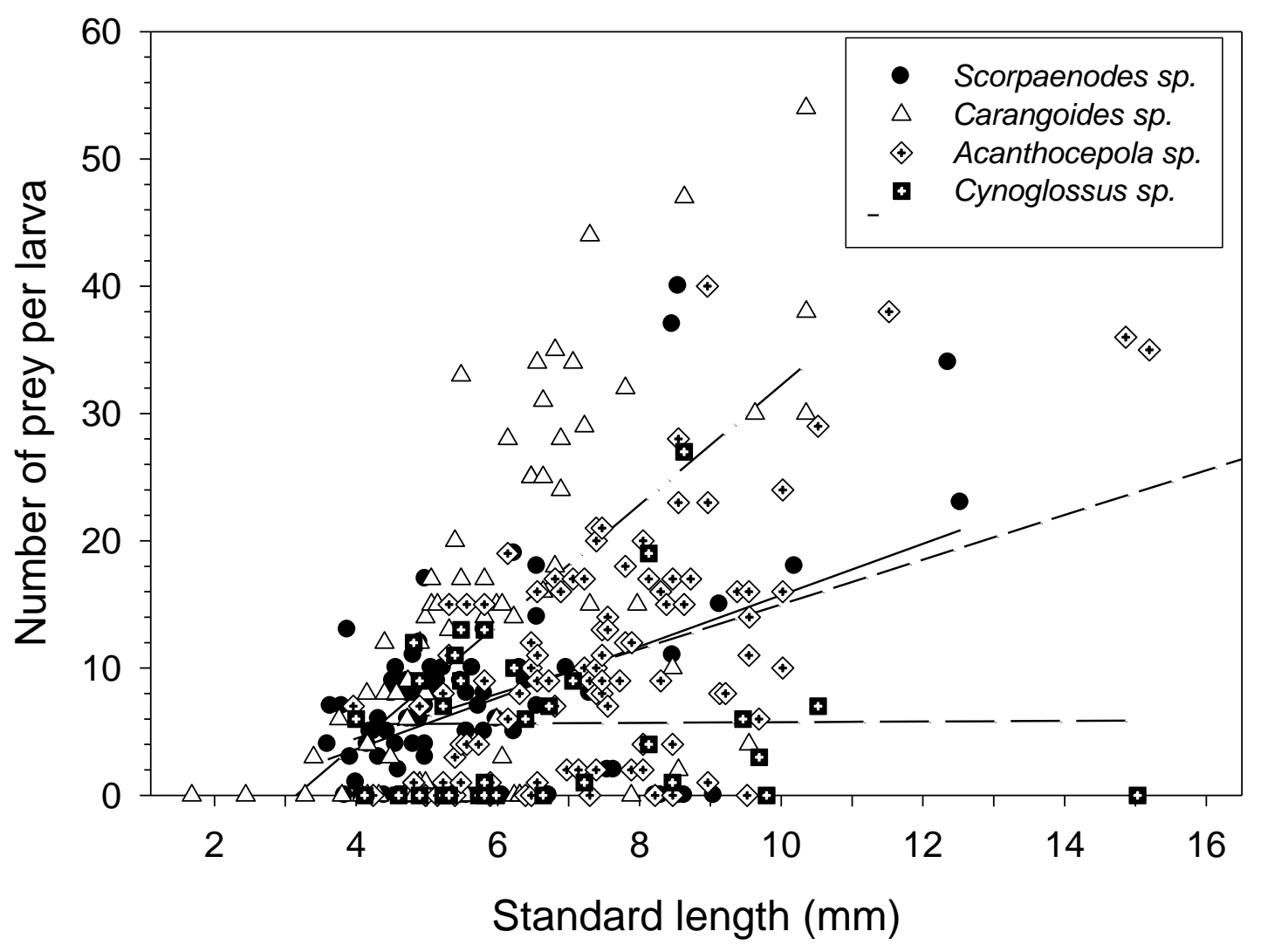


a) Scorpaenodes sp.

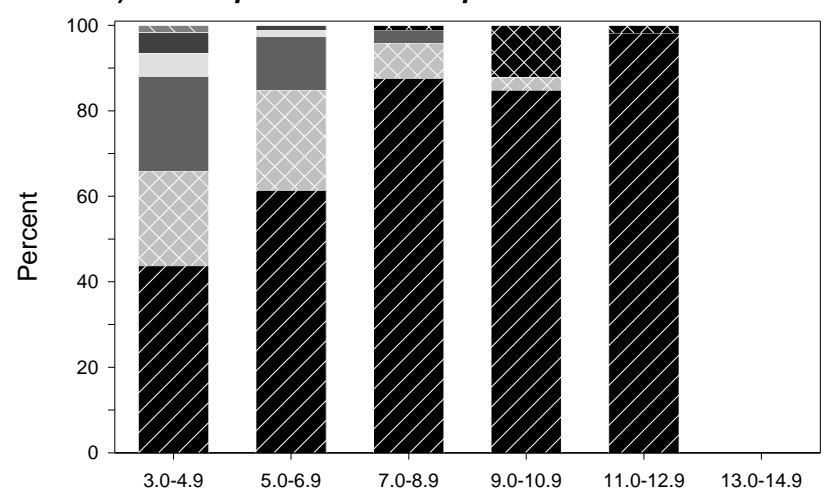

b) Carangoides sp.

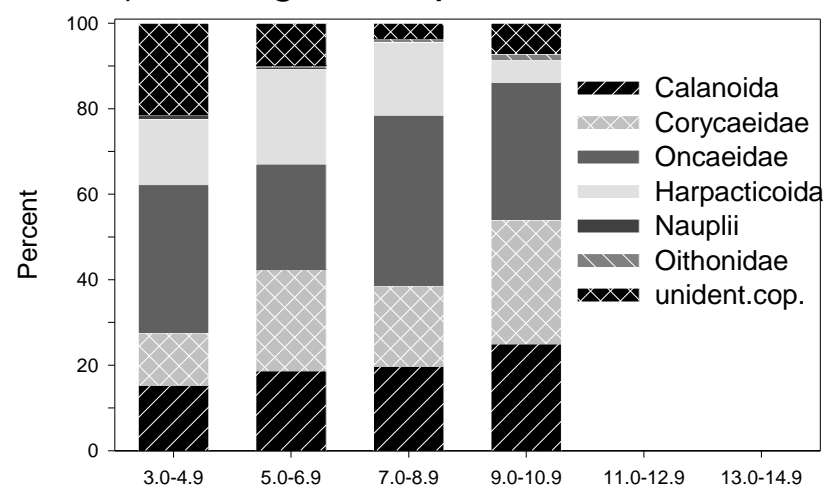

c) Acanthocepola sp.

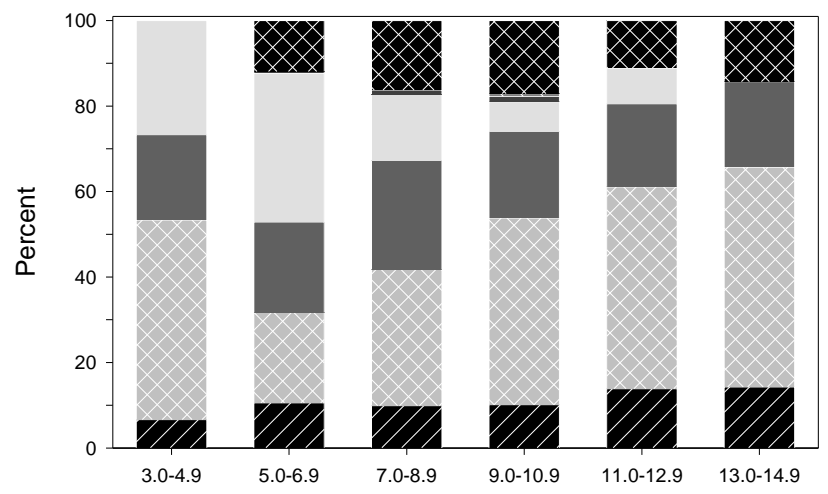

d) Cynoglossus sp.

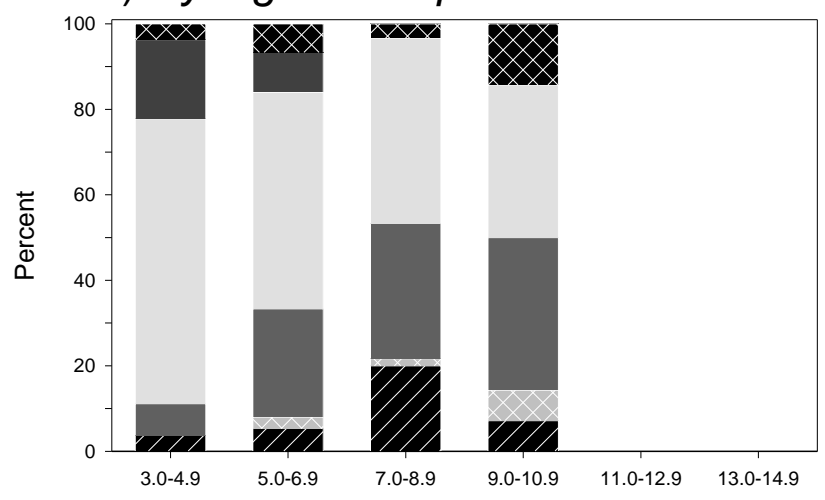

Figure 7

Larval length intervals $(\mathrm{mm})$ 

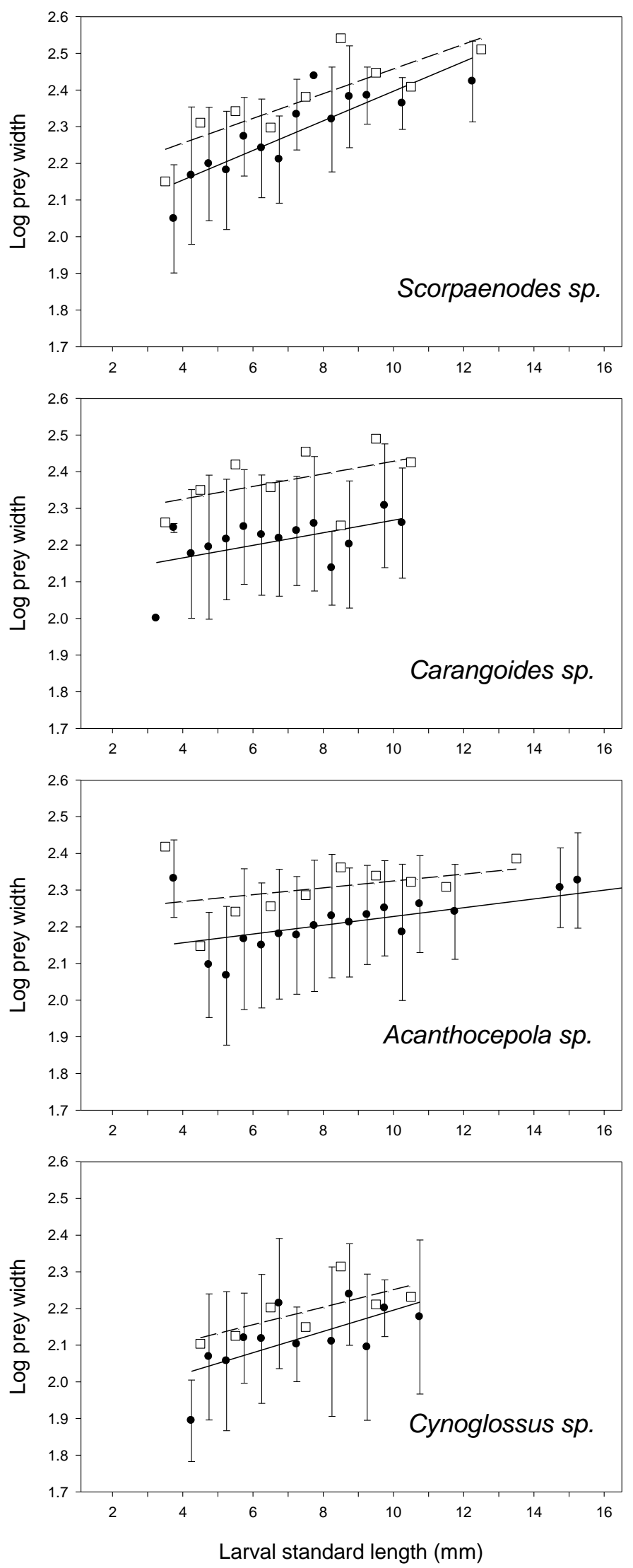

Figure 8 

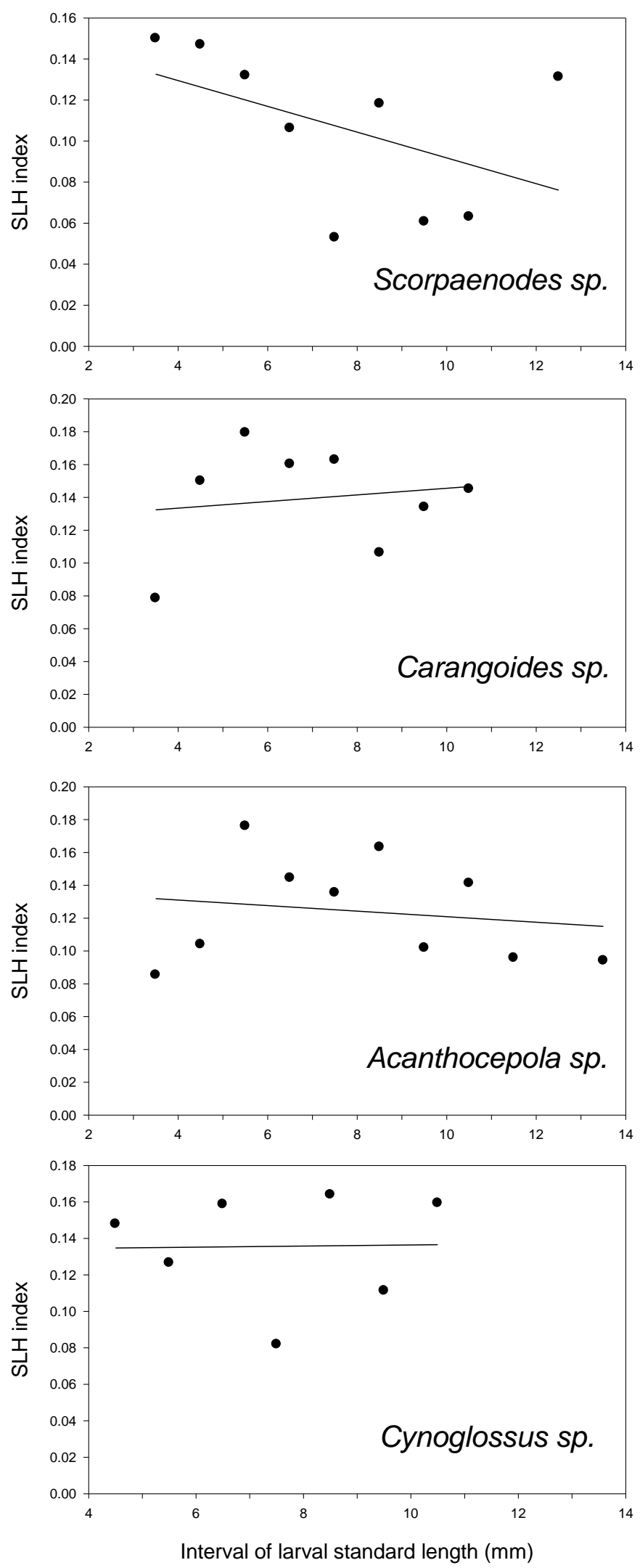

Figure 9 

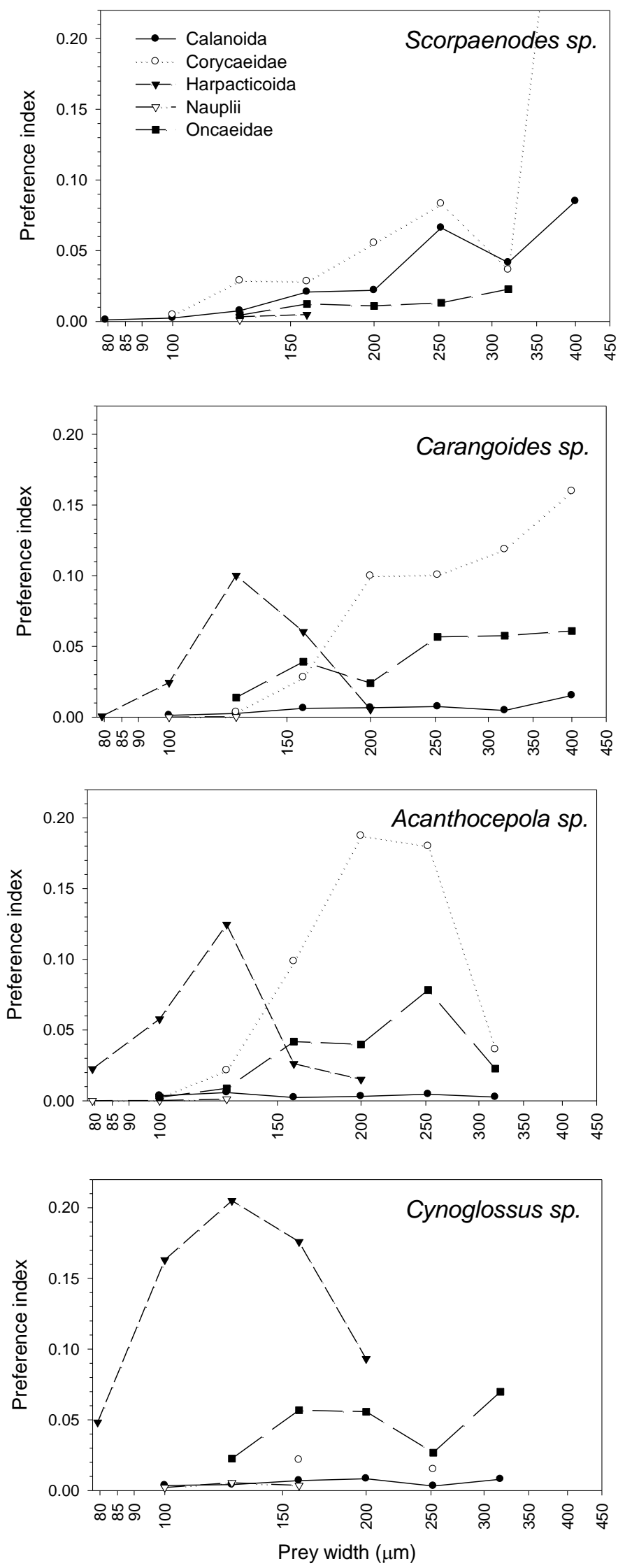

Figure 10 

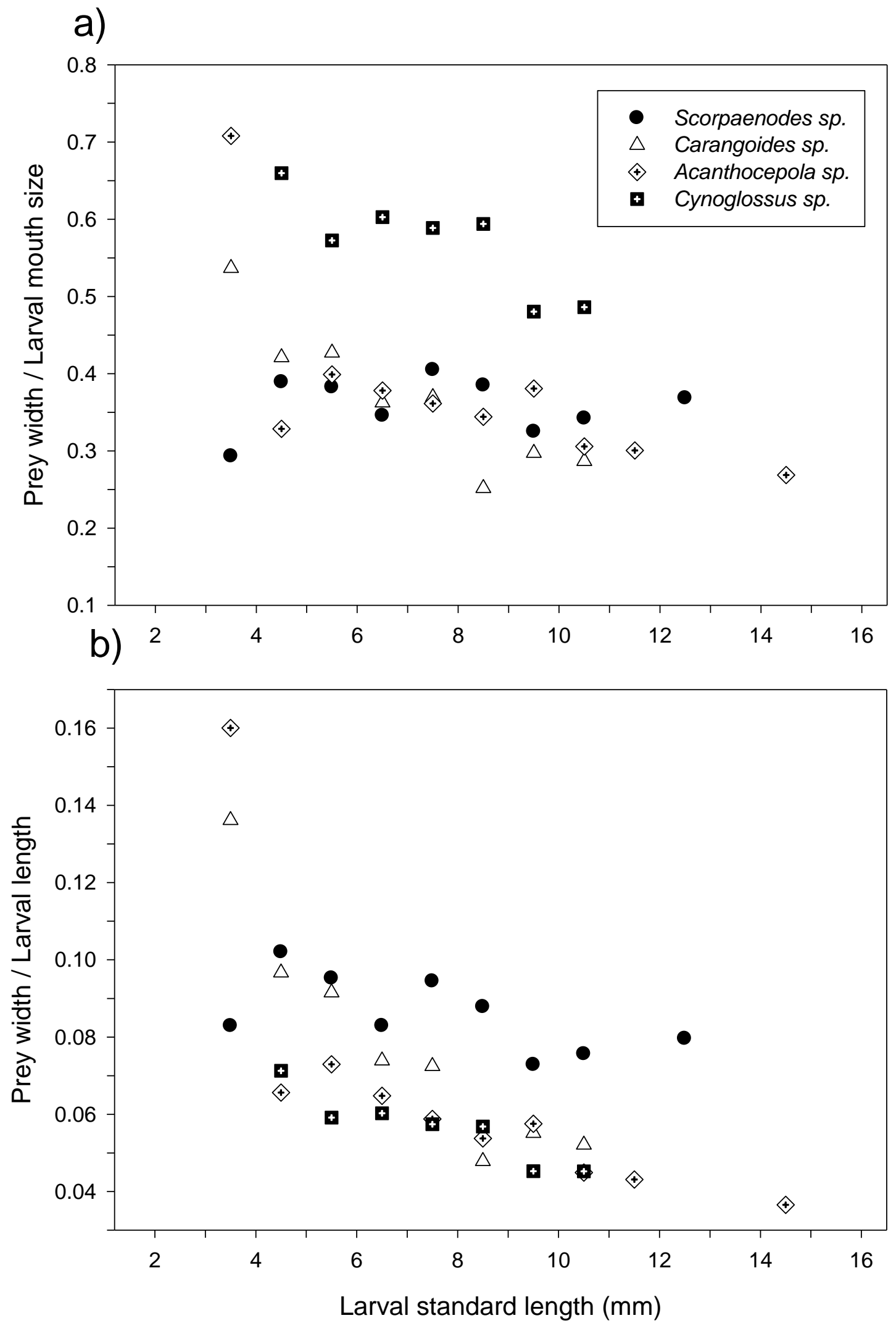

Figure 11 